\title{
Increased leptin levels in preeclampsia: associations with BMI, estrogen and SHBG levels
}

\author{
Acromite Michael, Ziotopoulou Mary, Orlova Christine, Mantzoros Christos
}

Division of Endocrinology, Beth Israel Deaconess Medical Center, Harvard Medical School, Boston, MA USA

\begin{abstract}
Leptin is secreted mainly by the white adipose tissue but is also synthesized in several non-adipose tissue organs including the placenta. Serum leptin levels are increased in normal pregnancies and are higher in preeclamptic than normal pregnant women. There is, however, a lack of empirical evidence of an independent association of serum leptin levels and preeclamsia. We have studied cross-sectionally $183^{\text {rd }}$ trimester preeclamptic women, $283^{\text {rd }}$ trimester and $302^{\text {nd }}$ trimester control women to confirm the reported increase of serum leptin in preeclampsia and to assess whether elevated leptin levels in preeclampsia increase the variance explained by body mass index (BMI), androgens, estrogens and/or sex hormone binding globulin (SHBG). Anthropometric, demographic and hormonal data were analyzed using linear and logistic regression models. Results: Leptin is significantly increased in preeclampsia by univariate analysis, but use of multivariate analysis indicates that the elevated leptin levels are not associated with preeclampsia independently from BMI, estrogens and SHBG. Conclusion: This study confirms that leptin levels are higher in women with preeclampsia than in controls and demonstrates that serum leptin levels do not add to the prediction of preeclampsia after accounting for BMI, estrogen and SHBG levels of preeclamptic women.
\end{abstract}

Key words: Leptin, Preeclampsia, Estrogens, BMI and SHBG

\section{INTRODUCTION}

Leptin, the circulating product of the ob gene, is secreted mainly by the white adipose tissue ${ }^{1,2}$ but is also synthesized in several non-adipose tissue organs including the placenta ${ }^{2}$. Recent studies have shown that serum leptin levels are increased in normal pregnancy and are higher in preeclamptic than normal

\footnotetext{
Address correspondence and requests for reprints to: Christos Mantzoros, MD DSc, Endocrinology, RN 325, Beth Israel Deaconess Medical Center, 99 Brookline Ave, Boston, MA 02215, Tel 617- 667 2151,

e-mail: cmantzor@caregroup.harvard.edu

Received 08-08-03, Revised 01-10-00, Accepted 26-10-03
}

pregnancies $^{3-7}$. Whether this increase is independent of changes in fat mass and/or other hormone levels, however, remains unknown since no previous study performed mutual adjustment for both anthropometric and hormonal confounders. More specifically, it has not yet been determined whether leptin levels are simply a marker for fat accumulation and mobiliza$\operatorname{tion}^{7}$ or whether the normal relationship between serum leptin and adiposity is disrupted in preeclamp$\operatorname{sia}^{4,8}$ due to the impact of other factors ${ }^{4,8}$. Since several other hormones influence both leptin levels ${ }^{9}$ and the development of preeclampsia ${ }^{3,10,11}$, the distinct possibility exists that other hormonal factors may be responsible for the higher leptin levels in pregnancies 
complicated by preeclampsia.

We have performed this study to confirm the reported increase of serum leptin in preeclampsia and to assess whether elevated leptin levels are independently related to preeclampsia after statistical correction for BMI, androgens and/or estrogen levels.

\section{SUBJECTS AND METHODS}

\section{Subjects}

We studied 76 primigravida women with singleton pregnancies at North Oakland Medical Centers who were informed and consented to participate, as previously described ${ }^{10}$. The study population consisted of 18 women in the third trimester of pregnancy, in labor or on the cusp of induction, with preeclampsia at the time of admission; 28 healthy, normotensive women in third-trimester labor; and 30 healthy normotensive women in second trimester who were observed until an uneventful delivery. All patients were enrolled from the labor and delivery department at North Oakland Medical Centers by one of the authors (M.A.). All women included in the study were taking a multivitamin supplement with iron, and none were receiving or had received antihypertensive medications or exogenously administered hormones. None of the subjects had any history of hypertension, hyperandrogenism or polycystic ovarian disease. Patients were excluded for medical conditions antedating pregnancy, such as hypertension, diabetes and systemic lupus erythematosus.

\section{Protocol}

Preeclampsia was defined as new onset hypertension diagnosed after 20 weeks ${ }^{12}$ gestation with either systolic blood pressures $\geq 140 \mathrm{mmHg}$, diastolic blood pressures $\geq 90 \mathrm{mmHg}$ or both, occurring on 2 occasions $\geq 6$ hours apart or in association with significant proteinuria ( $\geq 300 \mathrm{mg} / 24 \mathrm{~h}$ ). Venous blood samples were collected, labeled and centrifuged promptly. Serum samples were stored at $-70^{\circ} \mathrm{C}$ until determination.

\section{Hormone measurements}

Total and free testosterone, dehydroepiandrosterone sulfate (DHEAS) and estradiol were determined in duplicate by means of commercially available radioimmunoassays (Diagnostic Products Corp, Los Angeles, CA), and sex hormone binding globulin
(SHBG) was determined in duplicate by means of enzyme-linked immunosorbent assay (Wallac Inc, Gaithersburg, MD). Leptin was also determined in duplicate by means of commercially available radioimmunoassay (Linco Research Inc, St. Charles, MO). The sensitivity and the intra-assay and interassay coefficients of variation of the assays used were, respectively, as follows: testosterone, $4.0 \mathrm{ng} / \mathrm{dl}, 4.0 \%$ to $7.0 \%$, and $5.9 \%$ to $7.3 \%$; DHEAS, $1.1 \mathrm{ug} / \mathrm{dl}, 6.0 \%$ to 9.8, and $4.9 \%$ to $9.5 \%$; estradiol, $1.4 \mathrm{pg} / \mathrm{ml}, 4.0 \%$ to $5.0 \%$, and $3.5 \%$ to $5.5 \%$; sex hormone binding globulin, $0.5 \mathrm{nmol} / \mathrm{l}, 1.4 \%$ to $1.8 \%$, and $8.2 \%$ to $10.0 \%$; leptin $0.5 \mathrm{ng} / \mathrm{ml}, 3.4 \%$ to $8.3 \%$, and $3.0 \%$ to $6.2 \%$. No significant cross-reactivity was observed between the hormones measured. The cross-reactivity for testosterone and DHEAS with all other sex hormones in this study was $<0.1 \%$. Serum values were reported as mean \pm SEM for each group.

\section{Statistical Analysis}

Comparisons of hormonal concentrations between groups were performed using the Student's $t$ test and correlations between the study variables were assessed using Spearman correlation coefficients. Nominal variables, including the sex distribution of the neonates in the study groups, were analyzed using the $x^{2}$ test. Multivariate adjustment was performed using unconditional logistic regression analysis and multiple regression analysis as appropriate. Statistical analysis was performed with the SPSS statistical package (SPSS, SPSS Inc, Chicago, IL).

\section{RESULTS}

\section{Study variables in preeclamptic patients and controls}

Mean maternal age, mean gestational age and body mass index were not significantly different between the two third trimester groups (preeclamptics and controls) (Table 1a). In addition, the sex distribution of the neonates was not significantly different in the two third trimester study groups (data not shown).

In contrast, women in the second trimester of their pregnancies tended to have lower BMI in comparison to the third trimester preeclamptics, but this difference did not achieve statistical significance at the conventional $p=0.05$ level $(p=0.07)$ (Table 1a).

Serum hormone concentrations in the three study 
Table 1. Baseline characteristics of the study sample

\begin{tabular}{|c|c|c|c|c|c|c|c|c|c|}
\hline \multirow[b]{2}{*}{ Age (years) } & \multicolumn{3}{|c|}{$\begin{array}{c}\mathbf{3}^{\text {rd }} \text { trimester } \\
\text { Preeclamptic subjects } \\
(n=18)\end{array}$} & \multicolumn{3}{|c|}{$\begin{array}{c}\mathbf{3}^{\text {rd }} \text { trimester } \\
\text { Control subjects } \\
(n=28)\end{array}$} & \multicolumn{3}{|c|}{$\begin{array}{c}2^{\text {nd }} \text { trimester } \\
\text { Control subjects } \\
(n=30)\end{array}$} \\
\hline & 23.11 & \pm & 1.53 & 21.73 & \pm & 0.93 & 21.07 & \pm & 1.00 \\
\hline Height $(\mathrm{cm})$ & 159.10 & \pm & 1.73 & 162.70 & \pm & 1.24 & 162.60 & \pm & 1.24 \\
\hline Weight (kg) & 82.90 & \pm & 4.36 & 80.05 & \pm & 2.22 & 78.25 & \pm & 3.10 \\
\hline BMI $\left(\mathrm{kg} / \mathrm{m}^{2}\right)$ & 32.55 & \pm & 1.39 & 30.44 & \pm & 0.80 & 29.45 & \pm & 0.98 \\
\hline EGA & 36.56 & \pm & 0.63 \#\#\# & 37.90 & \pm & 0.622 \#\#\# & 27.17 & \pm & 0.39 \\
\hline \multicolumn{10}{|l|}{ Ethnic group: } \\
\hline White & \multicolumn{3}{|c|}{15} & \multicolumn{3}{|c|}{20} & \multicolumn{3}{|c|}{22} \\
\hline Black & \multicolumn{3}{|c|}{3} & \multicolumn{3}{|c|}{10} & \multicolumn{3}{|c|}{8} \\
\hline \multicolumn{10}{|c|}{ b. Hormonal Characteristics (mean values \pm SEM) } \\
\hline Hormones & \multicolumn{3}{|c|}{$\begin{array}{c}\mathbf{3}^{\text {rd }} \text { trimester } \\
\text { Preeclamptic subjects } \\
(n=18)\end{array}$} & \multicolumn{3}{|c|}{$\begin{array}{c}3^{\text {rd }} \text { trimester } \\
\text { Control subjects } \\
(n=28)\end{array}$} & \multicolumn{3}{|c|}{$\begin{array}{c}2^{\text {nd }} \text { trimester } \\
\text { Control subjects } \\
(n=30)\end{array}$} \\
\hline Leptin (ng/ml) & 24.56 & \pm & $5.03 *$ & 14.96 & \pm & 1.95 & 18.34 & \pm & 3.19 \\
\hline $\mathrm{E}_{2}(\mathrm{pg} / \mathrm{ml})$ & 36353.33 & \pm & 3787.36 \#\#\# & 33780.80 & \pm & 2598.53 \#\# & 16179.67 & \pm & 1559.35 \\
\hline $\mathrm{T}(\mathrm{ng} / \mathrm{dL})$ & 213.56 & \pm & 25.89* \#\#\# & 154.46 & \pm & 14.82 \#\# & 89.27 & \pm & 9.27 \\
\hline Free T (ng/dL) & 0.46 & \pm & $0.09 * \# \#$ & 0.29 & \pm & 0.03 \# & 0.20 & \pm & 0.02 \\
\hline $\mathrm{SHBG}(\mathrm{nmol} / \mathrm{L})$ & 544.62 & \pm & 42.71 & 581.69 & \pm & 28.95 & 521.70 & \pm & 34.46 \\
\hline DHEAS $(\mu \mathrm{g} / \mathrm{dl})$ & 171.00 & \pm & 14.79 & 175.50 & \pm & 23.60 & 136.07 & \pm & 13.26 \\
\hline
\end{tabular}

Data are presented as means $+/$-Standard Errors (SE)

\#\#\# $<0.0001$ compared to the $2^{\text {nd }}$ trimester control subjects, EGA (Estimated Gestational Age)

* 0.05 compared to the $3^{\text {rd }}$ trimester control group

\# 0.05, \#\# 0.01, \#\# \# $<0.001$ compared to the $2^{\text {rd }}$ trimester control group

$\mathrm{E}_{2}=$ Estradiol, $\mathrm{T}=$ Testosterone, $\mathrm{FT}=$ Free Testosterone, $\mathrm{SHBG}=$ Sex Hormone Binding Globulin, $\mathrm{DHEAS}=$ dehydroepiandrosterone sulfate

(To convert: Testosterone: from ng/dl to nmol/L, Free Testosterone from ng/dl to pmol/L, Estradiol from pg/ml to pmol/L, DHEAS from $\mu \mathrm{g} / \mathrm{dl}$ to $\mu \mathrm{mol} / \mathrm{L}$ please multiply by convesion factor $0.0347,34.7,3.67$ and 0.0272 , respectively).

groups are presented in Table 1b. Leptin levels were significantly higher in the preeclamptic group $(\mathrm{p}<0.05)$ compared to the third trimester controls. Testosterone and free testosterone levels were also significantly higher in the preeclamptic group compared to the third trimester control women $(\mathrm{p}<0.05)$. Third trimester control subjects had significantly higher estradiol, testosterone and free testosterone levels than their second trimester controls $(\mathrm{p}<0.01$, $\mathrm{p}<0.01$ and $\mathrm{p}<0.05$, respectively), and estradiol, testosterone and free testosterone were all higher in the third trimester preeclamptic subjects when compared with the second trimester controls $(\mathrm{p}<0.001, \mathrm{p}<0.001$ and $p<0.01$, respectively). However, no significant differences in the sex hormone binding globulin or $\mathrm{DH}-$
EAS levels were observed among these groups.

\section{Correlations among leptin and anthropometric and hormonal factors}

Table 2 shows Spearman correlation coefficients among the study hormonal variables. Leptin levels are significantly associated with estrogen and SHBG levels, indicating that these two hormonal factors could potentially confound the association between leptin and preeclampsia. In addition, it is possible that even non-significant differences, i.e the BMI differences among the study groups observed in this study, could contribute to confounding the association between leptin and preeclampsia and thus these variables should also be included in multivariable models. 
Table 2. Spearman correlation coefficients among leptin and the other measured hormones among third trimester controls

\begin{tabular}{|c|c|c|c|c|c|c|c|c|}
\hline & Leptin & Age & BMI & E2 & $\mathbf{T}$ & Free $T$ & SHBG & DHEAS \\
\hline \multicolumn{9}{|l|}{ Leptin } \\
\hline Age & 0.373 & & & & & & & \\
\hline BMI & $0.482^{*}$ & 0.083 & & & & & & \\
\hline E2 & 0.044 & $-0.472^{*}$ & -0.042 & & & & & \\
\hline $\mathrm{T}$ & 0.188 & $-0.460 *$ & -0.030 & $0.662^{* *}$ & & & & \\
\hline Free $T$ & -0.158 & $-0.426^{*}$ & 0.139 & 0.368 & $0.722 * *$ & & & \\
\hline SHBG & $0.471^{*}$ & 0.062 & -0.082 & 0.102 & 0.076 & $-0.481 *$ & & \\
\hline DHEAS & 0.072 & -0.272 & -0.175 & $0.576^{* *}$ & $0.386^{*}$ & 0.241 & 0.046 & \\
\hline
\end{tabular}

BMI, body mass index; EGA, estimated gestational age; E2, estradiol; T, testosterone; SHBG, sex hormone binding globulin; DHEAS, dehydroepiandrosterone sulfate.

*Correlation is significant at the 0.05 level (2-tailed).

${ }^{* *}$ Correlation is significant at the 0.01 level (2-tailed).

In this study we have confirmed that leptin levels are higher in preeclamptics by univariate analysis, as previously described ${ }^{4-7}$. To determine whether leptin levels are increased in preeclamptic subjects independently of BMI, race, height, sex steroids and SHBG, we ran a multiple regression analysis model with log leptin as the dependent variable and all variables shown in Table 3 as the independent variables. As indicated in Table 3, after adjustment for all potentially confounding variables shown in Table 3 , but not BMI, the study group (preelampsia vs. third trimester controls) is an independent and significant predictor of serum leptin levels. However, when BMI is entered in the multiple regression analysis model in addition to the above demographic and hormonal predictors to adjust for the effect of fat accumulation, the variable study group is no longer an independent predictor of serum leptin levels when entered in the model in addition to BMI. In contrast, estradiol and SHBG levels remain significant predictors of leptin levels. To confirm these findings, we ran logistic regression models with the study group (preeclamptics vs. third trimester controls) as the dependent variable and leptin as well as the other study variables as additional predic-

Table 3. Multiple linear regression analysis

\begin{tabular}{|c|c|c|c|c|c|c|}
\hline \multirow{2}{*}{$\begin{array}{l}\text { Independent } \\
\text { Variable }\end{array}$} & \multirow{2}{*}{$\begin{array}{c}\text { Standardized } \\
\text { Regression } \\
\text { Coefficient }^{\mathrm{a}}\end{array}$} & \multirow{2}{*}{$\begin{array}{c}\text { Two tailed } \\
\text { P-value }^{\mathrm{a}}\end{array}$} & \multicolumn{2}{|c|}{ Multiple Regression Coefficient ${ }^{\mathrm{b}}$ (SE) } & \multirow{2}{*}{$\begin{array}{c}\text { Standardized } \\
\text { Regression } \\
\text { Coefficient }^{\mathbf{b}}\end{array}$} & \multirow{2}{*}{$\begin{array}{c}\text { Two tailed } \\
\text { P-value }\end{array}$} \\
\hline & & & $(\beta)$ & $\overline{\mathrm{SE}(\boldsymbol{\beta})}$ & & \\
\hline Group & -0.036 & 0.03 & -0.140 & 0.111 & -0.236 & 0.218 \\
\hline Age & -0.11 & 0.61 & 0.00058 & 0.012 & -0.011 & 0.963 \\
\hline Height & 0.31 & 0.70 & 0.01289 & 0.008 & 0.292 & 0.123 \\
\hline BMI & & & 0.00688 & 0.013 & 0.110 & 0.602 \\
\hline Race & -0.30 & 0.70 & -0.0188 & 0.122 & -0.298 & 0.136 \\
\hline E2 & -0.58 & 0.08 & -0.0000131 & 0.000 & -0.571 & 0.035 \\
\hline $\mathrm{T}$ & 0.13 & 0.45 & 0.0007779 & 0.001 & 0.236 & 0.271 \\
\hline SHBG & 0.37 & 0.04 & 0.00112 & 0.001 & 0.497 & 0.042 \\
\hline DHEAS & 0.10 & 0.57 & 0.004353 & 0.001 & 0.143 & 0.475 \\
\hline
\end{tabular}

Group: Preeclampsia vs. $3^{\text {rd }}$ trimester control status

a adjusted for all variables shown except for BMI

${ }^{\mathrm{b}}$ adjusted for all variables shown

E, Estradiol; T, Testosterone; FT, Free Testosterone; SHBG, Sex Hormone Binding Globulin; DHEAS, dehydroepiandrosterone sulfate. 


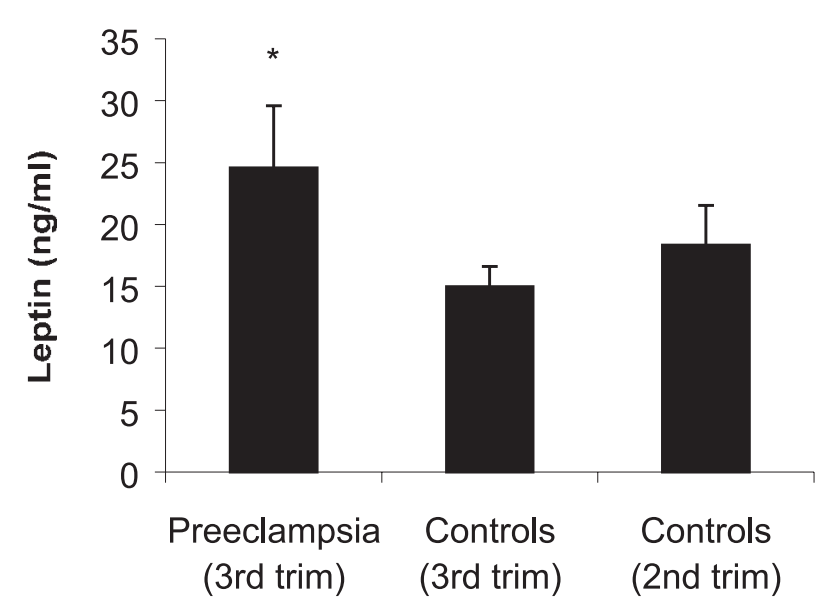

$* p<0.05$ compared to the $3^{\text {rd }}$ trimester controls

Figure 1. Leptin levels in patients with preeclampsia, $2^{\text {nd }}$ and $3^{\text {rd }}$ trimester controls.

tor variables (data not shown). A similar picture emerged. Leptin is significantly increased in preeclamspsia by univariate analysis, but after adjustment for the other study variables, leptin levels are not associated with preeclampsia, indicating that the elevated leptin levels shown by univariate analysis could possibly reflect an underlying relationship of leptin levels with BMI, SHBG and estrogens.

\section{DISCUSSION}

Preeclampsia affects approximately 5-10\% of all pregnant women ${ }^{13}$ and is a major cause of maternal morbidity and mortality during pregnancy in the developed world ${ }^{14}$. It is associated with significant alterations of maternal physiologic characteristics and metabolism manifesting itself primarily as hypertension with arteriolar vasoconstriction ${ }^{15}$. Although the pathophysiology of preeclampsia has not yet been fully elucidated, hormonal factors as well as vascular and hemostatic hyperreactivities involving the renin-angiotensin system, eicosanoids, and platelets have all been implicated ${ }^{16,17}$. Steroid levels and recently leptin have been reported to be abnormal in women with preeclampsia $^{3-7,71,18}$.

Leptin, a recently identified hormone, is mainly secreted by the white adipose tissue ${ }^{19}$ but recent evidence proved that this hormone is also secreted by the placenta ${ }^{2}$. Leptin is produced and secreted from placental trophoblast cells into the maternal circulation in considerable amounts ${ }^{2,20}$, contributing substan- tially to circulating plasma levels. Since obesity and preeclampsia share common features, such as glucose intolerence, insulin resistance ${ }^{21}$, hyperlipidemia ${ }^{22}$ and hypertension, and since obesity is an independent risk factor for preeclampsia, several studies have focused on the relation between the adipocyte secreted hormone leptin and preeclampsia ${ }^{3-7}$. These studies have reported leptin levels to be higher in preeclamptic women $^{3-7}$ (although in one study the difference did not achieve statistical significance ${ }^{7}$ ) and have demonstrated increased leptin expression in placental tissues from preeclamptic women compared to age matched controls $^{5}$. Thus, it has been suggested that leptin, derived either from adipose tissue or the placenta, may be involved in the pathogenesis of preeclampsia ${ }^{4}$. Longitudinal studies have documented that leptin levels increase with increasing gestational age ${ }^{23,24}$ or remain stable between the $2^{\text {nd }}$ and $3^{\text {rd }}$ trimester ${ }^{25}$, as in this study. In addition, leptin's relationship with BMI changes as gestational age progresses ${ }^{26}$, indicates that with progressing gestational age either the placenta produces relatively more leptin than the adipose tissue or that increasing levels of other hormones affect leptin levels. Only one previous study performed mutual adjustment to consider simultaneously more than one predictor of leptin. This study, which examined whether leptin levels are elevated in preeclampsia independently of other potentially confounding factors such as gestational age and body fat accumulation, demonstrated that plasma leptin levels in preeclamptic women are significantly elevated compared to gestational and body mass index matched normotensive women ${ }^{5}$. In addition, one previous study that examined the potential confounding role of hormonal factors indicated non-significant association with leptin by univariate analysis ${ }^{26}$. Thus, no previous study has examined whether sex steroids or their binding protein may influence serum leptin concentrations in preeclamptic women and/or whether the increased leptin level in preeclampsia is due to potential confounding by mutually adjusting for several hormone levels, age, race, gestational age and body fat accumulation.

It would be reasonable to speculate that hormonal predictors of preeclampsia may be influencing leptin levels. We have recently reported that total and free serum testosterone is significantly increased in preeclampsia ${ }^{10}$ and women with a documented history of preeclampsia have increased testosterone levels even 
17 years post-partum ${ }^{3}$. In addition, it has been reported that women with preeclampsia are also characterized by reduced levels of estrogens and insulin-like growth factor-1, and by elevated levels of progesterone, androgens, human chorionic gonadotropin, IGF-1 binding protein, corticotropin-releasing factor, cortisol and insulin ${ }^{11,18,27-28}$. It is also known that in addition to insulin and cortisol, both testosterone and estradiol alter serum leptin levels in humans ${ }^{9,29,30}$. Since all the above factors could confound the relationship between leptin and preeclampsia, we have controlled for potential confounding effects of body mass, age, race, SHBG and sex steroid hormones in this study. We confirmed earlier reports that serum leptin concentration in preeclamptic women are significantly higher than in normal third trimester pregnant women. More importantly, we showed that this increase is not independent of the confounding effect of BMI, sex steroids and SHBG.

The sample size of this study is comparable to that of other similar studies. Thus, the power of this study was not compromised by its size, despite the fact that preeclampsia represents a relatively small percentage of pregnancies, making it difficult to accrue a large number of cases and controls over a reasonable period of time. The finding of higher levels of leptin in pregnancies complicated by preeclampsia is consistent with clinical investigations showing higher leptin levels in preeclamptic women ${ }^{3-7}$ and in vitro observations that expression of leptin mRNA is increased in preeclampsia $^{5}$. More importantly, our findings show that controlling for estrogens, SHBG and BMI renders the difference in leptin levels non- significant. This is also consistent with previous findings showing that plasma leptin levels increase significantly over time in human pregnancies and the pattern of change in circulating leptin parallels the increase in estrogen levels as well as the process of fat accumulation and mobilization ${ }^{7}$.

Selection bias could not be an explanation for these results since we enrolled consecutively recruited subjects from the same source. The gestational age and estradiol levels of the patients with preeclampsia are relatively higher than what has been reported in most previous studies on severe preeclampsia, indicating that preeclampsia in this study was rather mild. It is thus expected that the edema of these subjects would have been milder, resulting in relatively less impor- tant misclassification of their BMI. This non-differential misclassification could not have influenced the results of this study. In addition, differential misclassification is unlikely given the blinded laboratory analysis. Although confounding was controlled through state-of-the-art statistical techniques, an additional potential effect of other serum hormones or unmeasured risk factors remains a possibility. This should be addressed by future prospective studies but, in any case, could not change the conclusions of this study, that the higher leptin levels in preeclampsia are not independent of alterations in BMI, estrogens and SHBG.

In summary, we confirm that leptin levels are higher in women with preeclampsia than in normal controls. More importantly, we demonstrate that the association between leptin and preeclampsia is not independent of altered BMI, estrogen and SHBG levels in preeclamptic women. Our cross-sectional study cannot prove or disprove a causal relationship between leptin and preeclampsia. Future research is needed to determine whether leptin is causally related to the development of preeclampsia and to study the exact mechanism by which the higher leptin levels, probably acting by activating the leptin receptors expressed in the placenta ${ }^{30}$, are linked with preeclampsia.

\section{REFERENCES}

1. Halaas JL, Gajiwala KS, Maffei M, et al, 1995 Weightreducing effects of the plasma protein encoded by the obese gene. Science 269: 543-546.

2. Masuzaki H, Ogawa Y, Sagawa N, et al, 1997 Nonadipose tissue production of leptin: leptin as a novel placenta-derived hormone in humans. Nat Med 3: 1029-1033.

3. Laivuori H, Kaaja R, Rutanen EM, Viinikka L, Ylikorkala O, 1998 Evidence of high circulating testosterone in women with prior preeclampsia. J Clin Endocrinol Metab 83: 344-347.

4. Williams MA, Havel PJ, Schwartz MW, et al, 1999 Preeclampsia disrupts the normal relationship between serum leptin concentrations and adiposity in pregnant women. Paediatr Perinat Epidemiol 13: 190-204.

5. Mise H, Sagawa N, Matsumoto T, et al, 1998 Augmented placental production of leptin in preeclampsia: possible involvement of placental hypoxia. J Clin Endocrinol Metab 83: 3225-3229.

6. McCarthy JF, Misra DN, Roberts JM, 1999 Maternal plasma leptin is increased in preeclampsia and positively correlates with fetal cord concentration. Am J Obstet Gynecol 180: 731-736.

7. Sattar N, Greer IA, Pirwani I, Gibson J, Wallace AM, 
1998 Leptin levels in pregnancy: marker for fat accumulation and mobilization? Acta Obstet Gynecol Scand 77: 278-283.

8. Kokot F, Wiecek A, Adamczak M, et al, 1999 Pathophysiological role of leptin in patients with chronic renal failure, in kidney transplant patients, in patients with essential hypertension, and in pregnant women with preeclampsia. Artif Organs 23: 70-74.

9. Mantzoros CS, 1999 The role of leptin in human obesity and disease: a review of current evidence. Ann Intern Med 130: 671-680.

10. Acromite MT, Mantzoros CS, Leach RE, Hurwitz J, Dorey LG, 1999 Androgens in preeclampsia. Am J Obstet Gynecol 180: 60-63.

11. Walsh SW, 1988 Progesterone and estradiol production by normal and preeclamptic placentas. Obstet Gynecol 71: 222-226.

12. American College of Obstetricians and Gynecologisis 1996 ACOG techical bulletin 219: Hypertension in pregnancy, Washington, The College.

13. Cunningham FG, MacDonald PC, Gant NF, et al 1997 Hypertensive disorders in pregnancy In: Cunningham FG, MacDonald PC, Gant NF, et al, (eds) Williams Obstetrics $19^{\text {th }}$ (ed) Stamford, CT: Appleton and Lange; pp, 693744.

14. Rochat RW, Koonin LM, Atrash HK, Jewett JF, 1988 Maternal mortality in the United States: report from the Maternal Mortality Collaborative. Obstet Gynecol 72: 9197.

15. Redman CW, 1991 Current topic: pre-eclampsia and the placenta. Placenta 12: 301-308.

16. Gant NF, Daley GL, Chand S, Whalley PJ, MacDonald PC, 1973 A study of angiotensin II pressor response throughout primigravid pregnancy. J Clin Invest 52: 26822689.

17. Zeeman GG, Dekker GA, 1992 Pathogenesis of preeclampsia: a hypothesis. Clin Obstet Gynecol 35: 317-337.

18. Innes KE, Byers TE, 1999 Preeclampsia and breast cancer risk. Epidemiology 10: 722-732.

19. Maffei M, Halaas J, Ravussin E, et al, 1995 Leptin levels in human and rodent: measurement of plasma leptin and ob RNA in obese and weight-reduced subjects. Nat Med 1: 1155-1161.

20. Senaris R, Garcia-Caballero T, Casabiel X, et al, 1997
Synthesis of leptin in human placenta. Endo 138: 45014504.

21. Fuh MM, Yin CS, Pei D, et al, 1995 Resistance to insulinmediated glucose uptake and hyperinsulinemia in women who had preeclampsia during pregnancy. Am J Hypertens 8: 768-771.

22. Hubel CA, McLaughlin MK, Evans RW, Hauth BA, Sims CJ, Roberts JM, 1996 Fasting serum triglycerides, free fatty acids, and malondialdehyde are increased in preeclampsia, are positively correlated, and decrease within 48 hours post partum. Am J Obstet Gynecol 174: 975-982.

23. Highman TJ, Friedman JE, Huston LP, Wong WW, Catalano PM, 1998 Longitudinal changes in maternal serum leptin concentrations, body composition, and resting metabolic rate in pregnancy. Am J Obstet Gynecol 178: 1010-1015.

24. Tamas P, Sulyok E, Szabo I, et al, 1998 Changes of maternal serum leptin levels during pregnancy. Gynecol Obstet Invest 46: 169-171.

25. Sivan E, Whittaker PG, Sinha D, Homko CJ, Reece EA, Boden G, 1998 Leptin in human pregnancy: the relationship with gestational hormones. Am J Obstet Gynecol 179: 1128-1132.

26. Schubring C, Englaro P, Siebler T, et al, 1998 Longitudinal analysis of maternal serum leptin levels during pregnancy, at birth and up to six weeks after birth: relation to body mass index, skinfolds, sex steroids and umbilical cord blood leptin levels. Horm Res 50: 276-283.

27. Laivuori H, Kaaja R, Koistinen H, et al, 2000 Leptin during and after preeclamptic or normal pregnancy: its relation to serum insulin and insulin sensitivity. Metabolism 49: 259-263.

28. Irwin JC, Suen LF, Martina NA, Mark SP, Guidice LC, 1999 Role of the IGF system in trophoblast invasion and pre-eclampsia. Hum Reprod 14: Suppl 2: 90-96.

29. Geisthovel F, Meysing A, Brabant G, 1998 C-peptide and insulin, but not C19-steroids, support the predictive value of body mass index on leptin in serum of premenopausal women. Hum Reprod 13: 547-553.

30. Lea RG, Howe D, Hannah LT, Bonneau O, Hunter L, Hoggard N, 2000 Placental leptin in normal, diabetic and fetal growth-related pregnancies. Mol Hum Reprod 6: 763-769. 